\title{
O AQUECIMENTO GLOBAL E A DIVULGAÇÃO CIENTÍFICA NAS REVISTAS SUPERINTERESSANTE E QUERO SABER
}

\author{
Igor Leandro Alves de Carvalho ${ }^{1}$ \\ Marcelo Borges Rocha
}

\begin{abstract}
RESUMO
O tema Aquecimento Global (AG) tem sido pauta de discussões em âmbito local e global, apresentando potencial de ultrapassar fronteiras, transitar em diferentes contextos e integrar a agenda dos meios de comunicação. Esta pesquisa teve por objetivo investigar como o AG é abordado nas Revistas Superinteressante e Quero Saber, observando a abordagem que cada revista dá ao tema e, ainda, como contextualizam as questões relacionadas ao AG. Todas as edições no período de 2012 a 2017 foram verificadas, no intuito de mapear os artigos que, de alguma maneira, tratam da temática. As categorias de análise foram criadas à luz da Análise de Conteúdo. Os resultados revelam uma abordagem diversificada por ambas as revistas. 0 tema recebe diversos enfoques e possibilita a discussão em vários contextos, entre eles o político, o histórico e o socioeconômico. A diversidade de enfoque demonstra que o tema possui uma boa amplitude temática e um caráter interdisciplinar e transversal. Conseguir relacionar os conhecimentos científicos ao cotidiano do público não especialista também faz parte do papel social da divulgação científica (DC).
\end{abstract}

Palavras-chave: Divulgação científica. Aquecimento global. Mídia impressa. Revistas de divulgação científica.

\section{GLOBAL WARMING AND SCIENTIFIC DISSEMINATION IN SUPERINTERESSANTE AND QUERO SABER MAGAZINES}

\section{ABSTRACT}

The theme Global Warming (GW) has been the agenda of discussions at local and global level, presenting the potential to cross borders, move in different contexts and integrate the media agenda. This research aimed to investigate how the GW is approached in the magazines Superinteressante and Quero Saber, observing the approach that each journal gives to the theme and also how they contextualize the questions related to the GW. All editions in the period from 2012 to 2017 were verified, in order to map the articles that somehow deal with the theme. How analytics categories were created in the light of Content Analysis. The results reveal a diversified approach by both journals. The theme receives several approaches and allows discussion in several contexts, including: political, historical and socioeconomic. The diversity of focus demonstrates that the theme has a good thematic amplitude and an interdisciplinary and transverse character. Being able to relate scientific knowledge to the daily life of the non-specialist public is also part of the social role of Scientific dissemination (SD).

Keywords: Scientific dissemination. Global warming. Printed Media. Science communication journals.

RECEBIDO EM: 20/11/2019

ACEITO EM: 17/4/2020

\footnotetext{
1 Autor correspondente. Centro Federal de Educação Tecnológica Celso Suckow da Fonseca (Cefet-RJ). Av. Maracanã, 229 - Maracanã. CEP 20271110. Rio de Janeiro/RJ, Brasil. http://lattes.cnpq.br/0870279252444493. https://orcid.org/0000-0002-4178-4660. igor.leandro@yahoo.com.br

2 Centro Federal de Educação Tecnológica Celso Suckow da Fonseca (Cefet-RJ). Rio de Janeiro/RJ, Brasil. http://lattes.cnpq. br/5640018108479090. http://orcid.org/0000-0003-4472-7423
} 
Os temas ambientais fazem parte das discussões na esfera científica, política, econômica e midiática. Medidas de mitigação (que inferem até o ponto de ser possível aliviar os problemas causados pelo desenvolvimento mundial e possíveis formas de reverter esses problemas), capacidade adaptativa (diz respeito à capacidade de ajuste à mudança do clima com o intuito de dirimir os danos ambientais ou aproveitar a oportunidade ante o potencial prejuízo), principais problemas, causas e efeitos, são alguns dos pontos presentes nas pautas de discussão.

Oliveira et al. (2017) ressaltam que a visibilidade dos temas ambientais, sobretudo mudança climática e aquecimento global, aumentou a partir da adesão de economistas, políticos, empresas e opinião pública. Dessa forma, os temas ambientais deixam de ser discutidos apenas por especialistas da área, e passam a fazer parte do cotidiano social.

$\mathrm{O}$ aquecimento global está entre os temas que mais relacionam efeitos às causas oriundas de ações antrópicas por grande parte da comunidade científica (FERREIRA et al., 2017). Sendo pauta de discussões em âmbito local e global, faz parte da agenda dos meios de comunicação - mesmo que a veiculação seja prioritariamente reativa e com pouca profundidade (CALERO; VILCHES; GIL PEREZ, 2013) -, e detém a capacidade de ultrapassar as fronteiras da comunidade científica e adentrar em diversos territórios, principalmente das políticas públicas (COOK et al., 2013), além de suportar conflitos, tensões e contradições nas discussões que o envolve.

Para a mídia impressa as mudanças climáticas e o aquecimento global não são algo recente. De acordo com Loose e Carvalho (2015), existe uma frequência do tema na cobertura jornalística mundial a partir dos finais dos anos 80 e início dos 90 do século 20 até os dias atuais, que perpassa pela veiculação de eventos naturais extremos e debates políticos. Ainda segundo as autoras, a maneira como o tema é noticiado não reflete a urgência e a amplitude intrínsecas à questão na maioria das vezes, posto que a informação é construída a partir da hegemonia de vozes e sem a devida contextualização.

Essa falta de contextualização pode gerar, no leitor, um distanciamento que prejudica o interesse em participar da discussão, pois dificulta o reconhecimento das questões climáticas no seu cotidiano. Se o reconhecimento no cotidiano é prejudicado, o sentimento de pertencimento, e o consequente enfrentamento, também são.

Nesse contexto, a divulgação científica (DC), que pode ser entendida como o compartilhamento do saber (conhecimento científico) por meio de diversas formas de divulgação e com um propósito de proporcionar a participação dos sujeitos (cidadãos) nos rumos da coletividade, nos assuntos tecnocientíficos, ambientais, sociais, etc., vem como resposta a essa falta de contextualização e ao caráter urgente do tema em análise. Para isso, as práticas de divulgar ciência foram pensadas com o objetivo de demonstrar os processos de construção do conhecimento e os resultados de pesquisa, relacionando a outros contextos, com comportamento crítico e reflexivo.

Os recursos utilizados para estabelecer a comunicação do conhecimento científico ao público tende a favorecer o desenvolvimento da reflexão crítica e a participação da sociedade ou, pelo contrário, reforça a distância entre o público especialista e o público não especialista (geral). Sabbatini (2004) já mencionava pelo menos duas abordagens (modelos) que podem ser exploradas na comunicação pública da ciência e da 
tecnologia. O modelo mais usado para aumentar o apoio da sociedade às atividades de pesquisa, é o "modelo de déficit", que se apoia em um esquema linear tradicional de comunicação, caracterizado pelo emissor/transmissor/receptor. Trata-se de transmitir a maior quantidade de informações possíveis, em geral fatos, o que proporciona o distanciamento entre o público especializado e o leigo. Nessa abordagem, a comunicação acontece verticalmente (de cima para baixo), não se preocupando em transmitir o processo de construção do conhecimento de forma contextualizada, mas enviando um turbilhão de fatos ausentes de mudança de contexto de significado. Isto é, os procedimentos inerentes da construção do conhecimento científico, tais como elaboração de modelos, processos de análise de resultados e experimentação, não são valorizados.

A outra abordagem, discorrida por Sabbatini (2004), é a abordagem contextual, na qual o diálogo participa da geração do conhecimento. Se, por um lado, a abordagem anteriormente dita (modelo de déficit) é utilizada como objeto de persuasão, nesta abordagem contextual as necessidades e anseios dos envolvidos devem ser levados em consideração. Nesse sentido, a divulgação não deve promover a alienação do público não especializado, mas, sim, aperfeiçoar os processos democráticos e servir aos interesses da comunidade científica representada pelos pesquisadores, centros de pesquisa, institutos, academia, indústria, entre outros. Neste caso, o aspecto social da ciência é reconhecido.

Podemos encontrar outros modelos de comunicação (ou abordagem) na literatura, entretanto os modelos não se anulam e podem se manter atuais. Dependendo do contexto sociocultural, econômico e político, podem ser empregados de maneira combinada (OLIVEIRA; CARVALHO, 2015). É na prática que se percebe a predominância simbólica bem como os objetivos de cada forma de comunicação pública da ciência.

Com um olhar mais crítico sobre a maneira de comunicar os conhecimentos científicos, Silva (2006) sinaliza que a DC não é uma atividade unidirecional, tendo somente a interlocução entre o cientista e o não cientista. Existe também, segundo o autor, a interlocução entre os pares (cientistas), configurando, assim, uma complexidade maior em relação à comunicação. Ainda assim, se a atividade da DC for compreendida por esse caminho unidirecional de interlocução entre o cientista (produtor do conhecimento) e o público (consumidor desse conhecimento), a verticalidade seria evidente. De um lado, o "produtor do conhecimento científico numa posição de autoridade altamente legitimada" e do outro o "sujeito interessado em atualização cultural" (SILVA, 2006 p. 58). O autor, então, demonstra que a comunicação dos conhecimentos ao público é complexa, envolve diferentes atores e exige maior reflexão.

Rocha (2017) sinaliza que a DC busca informar o leitor justamente sobre os assuntos que permeiam a sociedade. Isso faz com que a sociedade tenha uma relação mais estreita com a ciência e tecnologia, uma vez que as informações recebidas pela sociedade fazem parte da dinâmica social, interferindo na maneira como o sujeito percebe o mundo e o modifica. 
Schmidt, Ivanova e Schäfer (2013) defendem a necessidade de ir além da investigação do grau de atenção da mídia sobre os temas ambientais, sendo relevante revelar como os esses temas são enquadrados e avaliados pela cobertura midiática, a ponto de inferir como a mídia pode influenciar na formulação das reações sociais e quais posições políticas preteridas são colocadas pelos veículos.

Dentro deste cenário, é importante refletir que tipo de informação está sendo divulgada e de que maneira isso acontece. Assim, esta pesquisa teve por objetivo investigar como o Aquecimento Global (AG) é abordado nas Revistas Superinteressante e Quero Saber, observando o enfoque dado ao tema pelas revistas e inferindo sobre a capacidade de contextualização de cada uma delas.

\section{METODOLOGIA}

Este trabalho é um recorte de uma pesquisa de dissertação que investigou o comportamento da DC no Brasil e em Portugal mediante as revistas de DC acerca do tema AG. Configura-se como uma pesquisa qualitativa ancorada na análise documental (LÜDKE; ANDRÉ, 1986; GODOY, 1995). A pesquisa qualitativa, segundo Godoy (1995), não se apresenta como uma proposta rigidamente estruturada, e, por isso, propostas de trabalho que explorem novos enfoques são permitidas pelos investigadores. Baseado nisso, "a pesquisa documental representa uma forma que pode se revestir de um caráter inovador, trazendo contribuições importantes no estudo de alguns temas" (GODOY, 1995, p. 21).

Todas as edições no período de 2012 a 2017 foram verificadas, no intuito de mapear os artigos que tratam da temática AG. O método da Análise de Conteúdo, que, segundo Bardin (2002, p. 38), é um "conjunto de técnicas de análise das comunicações que utiliza procedimentos sistemáticos e objetivos de descrição do conteúdo das mensagens", foi selecionado para analisar os textos. Para que o sentido (manifesto ou oculto) das comunicações seja compreendido criticamente por meio da análise, descrição e interpretação dos enunciados/mensagens dos textos, seguimos uma das possibilidades de categorização - uma marca desse método - propostas por Bardin (2002): a categorização a priori, decorrida do funcionamento direto dos pressupostos teóricos e hipotéticos.

As Revistas Superinteressante e Quero Saber possuem algumas características consideradas comuns no universo das revistas de DC, entre elas: ampla abrangência ao público por diversos caminhos; periodicidade de publicação (ambas publicam mensalmente); são publicações de editoras que possuem forte influência em seus respectivos países (Editora Abril e Editora Goody); possuem perfil semelhante; e, além disso, dentro da classificação proposta por Gomes (2000) de distinguir revistas de DC em revistas híbridas e revistas jornalísticas, ambas podem ser classificadas como jornalísticas (textos com autoria exclusiva de jornalistas). Essas e outras características oferecem possiblidades de discussão sobre a temática em questão e possíveis implicações em cada contexto social e educacional. É importante destacar que todo material da Revista Quero Saber para esta pesquisa foi possível por meio de um início de parceria com a Universidade do Minho (Portugal), que influenciou diretamente no recorte temporal deste estudo. As- 
sim, acreditamos justificar a escolha das revistas e a relevância de um estudo da mídia impressa com potencial de discutir as abordagens de revistas de DC em diversos contextos culturais.

A pesquisa completa que deu origem a este trabalho possui cinco categorias de análise. Para este trabalho utilizamos duas categorias dessas cinco: Temática e Abordagens e Contextos.

Na categoria temática o que se pretende investigar são os enfoques dados ao tema escolhido. Busca-se, aqui, explicitar como o autor apresenta o tema, qual importância é dada às questões colocadas e se há ou não a necessidade de conhecimentos implícitos para compreensão do texto. A maneira como o texto é organizado pode auxiliar na análise desta categoria, como os aspectos estruturais (extensão do texto, aprofundamento, encadeamento das informações, etc.).

$\mathrm{Na}$ categoria abordagens e contextos interessa-nos investigar de que maneira o fato noticiado (texto) está inserido nas diversas possibilidades de contexto. Esta categoria busca pesquisar se o texto está, ou não, inserido no contexto social, político, econômico, educacional, entre outros, e de que maneira isso é colocado ao leitor. Em outras palavras, busca-se investigar se o texto consegue estabelecer relação com outro contexto que não seja o científico.

\section{RESULTADOS E DISCUSSÃO}

Foram encontrados 24 textos - 9 da Superinteressante (Quadro 1) e 15 da Quero Saber (Quadro 2) - que tratam do tema AG. Optamos por apresentar os resultados por categoria. Além disso, para oferecer elementos de comparação entre as revistas demos preferência por apresentar (em cada categoria) os resultados das revistas em paralelo.

Quadro 1 - Informações dos artigos da Revista Superinteressante

\begin{tabular}{|c|c|c|}
\hline Código & Título & Publicação \\
\hline SUP01 & O futuro - como ele será: ambiente & Agosto/2012 \\
\hline SUP02 & $\begin{array}{c}\text { Experiência para tentar reverter o aquecimento global } \\
\text { pode resultar em catástrofe }\end{array}$ & Março/2013 \\
\hline SUP03 & Cientistas criam bactéria que come $\mathrm{CO}_{2}$ do ar & Maio/2013 \\
\hline SUP04 & Superbolha pode acelerar aquecimento global & Outubro/2013 \\
\hline SUP05 & Teremos cada vez mais tornados & Novembro/2013 \\
\hline SUP06 & Clima extremo & Março/2014 \\
\hline SUP07 & Superplanta faz mais fotossíntese & Maio/2014 \\
\hline SUP08 & Aquecimento global afeta a produtividade dos países & Dezembro/2015 \\
\hline SUP09 & Máquina transforma $\mathrm{CO}_{2}$ em comida & Outubro/2017 \\
\hline
\end{tabular}

Fonte: Elaboração própria. 
Quadro 2 - Informações dos artigos da Revista Quero Saber

\begin{tabular}{|c|c|c|}
\hline Código & Título & Publicação \\
\hline QS01 & Controlar o tempo & Março/2014 \\
\hline QS02 & Podemos travar o aquecimento global? & Agosto/2016 \\
\hline QSO3 & Poluição do ar & Agosto/2016 \\
\hline QSO4 & Alterações climáticas: toda a verdade & Agosto/2017 \\
\hline QS05 & $\begin{array}{c}\text { "Não há aquecimento global porque o tempo tem estado } \\
\text { mais frio" }\end{array}$ & Agosto/2017 \\
\hline QS06 & "Os cientistas discordam sobre as alterações climáticas" & Agosto/2017 \\
\hline QS07 & $\begin{array}{l}\text { "Alterações climáticas que hoje vemos são totalmente } \\
\text { naturais" }\end{array}$ & Agosto/2017 \\
\hline QS08 & $\begin{array}{c}\text { "O tempo extremo é um efeito direto das mudanças } \\
\text { climáticas" }\end{array}$ & Agosto/2017 \\
\hline QS09 & “O CO não é o problema, é o metano" & Agosto/2017 \\
\hline QS10 & "Os animais podem sempre adaptar-se" & Agosto/2017 \\
\hline QS11 & "Mais $\mathrm{CO}_{2}$ é bom porque as plantas precisam dele" & Agosto/2017 \\
\hline QS12 & "Tudo não passa de uma conspiração" & Agosto/2017 \\
\hline QS13 & "Alguns graus não farão diferença" & Agosto/2017 \\
\hline QS14 & "Nada podemos fazer para travar as mudanças" & Agosto/2017 \\
\hline QS15 & "As mudanças climáticas são geradas pelo Sol" & Agosto/2017 \\
\hline
\end{tabular}

Fonte: Elaboração própria.

A maneira como o tema AG é abordado nas revistas é diversificado. Essa diversificação pode ser percebida observando-se individualmente cada revista, ou comparando o comportamento das revistas entre si.

\section{TEMÁTICA}

Existe uma característica comum em todos os artigos da Superinteressante: em nenhum artigo o AG recebe o enfoque principal. Isso significa que os argumentos e colocações não apontam unicamente para a temática. A centralidade dos artigos é ocupada por outros temas. Na Revista Quero Saber essa característica não foi observada, pois esta aborda a temática com mais dinamicidade, colocando o tema como protagonista em alguns artigos.

Nos artigos analisados, o AG serve como ponto de partida (SUPO2, SUPO3, QSO6 e QS14) para a construção argumentativa dos fatos, causador de desequilíbrios ambientais observados (SUP04, SUP05 e SUP08) e coadjuvante (SUP01, SUP06, SUP07, SUP09, QS03, QS05, QS07, QS08, QS09, QS10, QS11, QS12 e QS15). O AG está presente em todos os artigos, mas a participação é em segundo plano; não é a de "ator principal". Até mesmo os artigos que citam o tema em seus títulos (SUPO2, SUPO4, SUPO8) colocam o 
AG para contextualizar, fundamentar ou trazer importância ao seu texto. No artigo QSO1 o AG, inicialmente, não recebe o enfoque principal, mas no desenvolvimento do texto torna-se protagonista. No artigo QSO2 o AG também não recebe o enfoque principal, e estabelecer relação do tema com as informações apresentadas no artigo não é simples. Os artigos nos quais o AG recebe o enfoque principal são QSO4 e QS13.

\section{Ponto de partida}

Sobre os artigos que utilizam o tema AG como ponto de partida, o SUP02, com o título "Experiência para tentar reverter o aquecimento global pode resultar em catástrofe", e subtítulo "Empresário norte-americano decide jogar 100 toneladas de sulfato de ferro no Oceano Pacífico e provoca o surgimento de uma mancha de fitoplâncton com

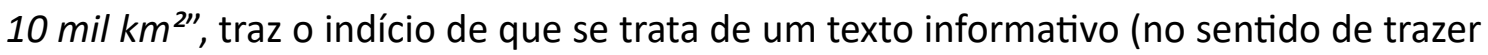
a informação sem se preocupar em influenciar na formação de opinião), cujo AG é ponto de partida para a construção do texto auxiliando no encadeamento dos argumento do autor. $O$ artigo inicia apresentando a causa do $A G$, seguida de uma hipótese para combater essa causa, e, finalmente, entra na questão central do texto: um empresário tentou testar a hipótese e acabou incentivando protestos na comunidade científica. $O$ texto concentra seu enfoque na discussão entre pesquisadores e o empresário mediante as possíveis consequências ambientais da atitude de verificar a hipótese. Neste artigo, apesar de não ser extenso, o autor dedica espaços para explicar as questões envolvidas e apresenta os lados da discussão.

Pode ser observado no artigo SUPO3 que o autor apresenta uma notícia valorizando os cientistas, e, ao mesmo tempo, sugerindo uma consequência na contramão da proposta dos cientistas. No seu título está a valorização "Cientistas criam bactéria que come o $\mathrm{CO}_{2}$ do $a r^{\prime}$, e, em seu subtítulo, está a sugestão contrária: "Micro-organismo criado em laboratório pode frear o aquecimento global - ou mergulhar a humanidade numa era glacial". O texto desenvolve-se, inicialmente, demonstrando a experiência feita pelos pesquisadores para chegar ao organismo em questão (bactéria modificada geneticamente), depois relaciona a bactéria com as plantas destacando a eficiência destas, e, ao final, expõe um risco: "Se a bactéria transgênica escapar e se reproduzir de forma descontrolada, poderia consumir $\mathrm{CO}_{2}$ em excesso e esfriar demais a atmosfera". $\mathrm{O}$ enfoque principal do texto é apresentar o sucesso dos pesquisadores em criar um organismo capaz de atuar no combate ao AG. Existe a preocupação em oferecer contextos e explicações, por exemplo: “(...) criatura que adora calor: a bactéria Pyrococcusfuriosus, que vive dentro de vulcões submarinos onde a temperatura chega a 100 graus" e "ele excreta ácido 3-hidroxipropiônico - que serve para fazer acrílico e é um dos compostos mais usados na indústria química". Suas explicações e contextos demonstram certo aprofundamento de argumentos, e o texto não é extenso (3 parágrafos com 7 linhas em média).

Em QS06 e QS14 o AG serve para introduzir a discussão, mas não participa do conjunto de argumentos principais. A temática aparece no início dos dois artigos. Em QS14 de forma tímida: "Detetámos nossa influência sobre as alterações climáticas cedo". Logo em seguida o enfoque volta-se para as ideias e tecnologias que buscam mitigar os efeitos das mudanças de temperatura, como: "pulverizando partículas refletoras na atmos- 
fera", "encorajando o crescimento de algas marinhas" e "refletir parte da luz solar para o espaço". Em QSO6 é possível ver esse comportamento de forma mais evidente. Logo na frase inicial é apresentada a seguinte informação: “A Terra está a ficar mais quente; registros térmicos com mais de cem anos de organizações independentes mostram que o planeta está a aquecer". Depois dessa frase os argumentos e informações apontam para o consenso entre os especialistas. $O$ artigo defende que não há divergência entre os cientistas em relação à realidade das mudanças do clima. Nesse ponto é quase um consenso na comunidade científica que as alterações climáticas, de fato, existem e exercem forte influência na dinâmica social. Sobre a(s) causa(s), entretanto, existem, pelo menos, três grupos que se contrapõem em discussão (SANTOS; GALVÍNCIO; MOURA, 2010): o primeiro grupo defende que há uma relação direta do AG com a exploração intensa do ambiente natural pelas ações antrópicas; o segundo grupo caminha no sentido contrário, defendendo que a mudança da temperatura global está associada a fatores exclusivamente naturais; e o terceiro grupo busca trazer uma ponderação entre as duas linhas anteriores, considerando que defende a ideia que o AG tem suas causas na combinação de fatores antropogênicos e naturais.

$O$ fato de esses artigos utilizarem o tema AG como ponto de partida para a construção dos seus argumentos e veiculação de informações é natural (e até esperado), pois a temática é ampla, controversa (principalmente em relação às causas), faz parte da agenda de diversos setores da sociedade e, por isso, não é tratada apenas nos editoriais científicos. Temas como o AG têm potencial para ganhar enfoques e desdobramentos diversos, além de servir como "gancho jornalístico", que pode ser entendido como elemento selecionador de pauta (WOITOWICZ, 2017).

\section{Coadjuvante}

A maioria dos artigos analisados coloca o tema em segundo plano, servindo para contextualizar ou trazer relevância ao artigo. Por exemplo, os artigos QSO9, QS10 e QS11 dão enfoque a temas secundários ao $A G$, isto é, os temas estão relacionados ao AG, mas ganham projeção maior que o próprio AG. Semelhantemente, nesse mesmo sentido de dar mais destaque aos conhecimentos e fatos oriundos de temas secundários, os artigos SUP07 e SUP09 são curtos, sem rebuscamentos, são diretos, e conseguem explorar as informações trazendo ao público não especializado conhecimentos e fatos que são distantes do seu cotidiano.

QS09, QS11 e SUP09 focam na discussão dos níveis de $\mathrm{CO}_{2}$. Em SUP09 desde o início apresenta esse gás como "o grande vilão do aquecimento global", e, a partir disso, informa ao leitor que existem duas maneiras de combater esse vilão: "queimar menos combustiveis fósseis, para emitir menor quantidade desse gás, e aumentar a área coberta por florestas". As duas maneiras, segundo o texto, enfrentam resistência na área econômica, então o artigo apresenta uma alternativa para combater o gás carbônico sem enfrentar essa resistência. Essa alternativa consiste no processo desenvolvido por cientistas, quando o gás é capturado e bombeado para tanques que contêm bactérias geneticamente modificadas, responsáveis por consumir o gás e transformá-lo em proteína. Todo o processo é demonstrado com simplicidade, com explicações de fácil entendimento e com uma lógica estrutural. 
O texto QS10 foca na discussão acerca da adaptação e extinção de espécies influenciadas pelas mudanças climáticas, e SUPO7 traz o AG somente na parte final do texto de uma forma explícita: "Elas sugariam muito $\mathrm{CO}_{2}$ do ar, o que ajudaria a brecar o aquecimento global". Em nenhuma outra parte o texto relaciona o AG à principal informação do artigo, que é a "criação de uma planta que faz $30 \%$ mais fotossíntese". Parece-nos que o intuito de mencionar o tema é trazer relevância à técnica desenvolvida pelos especialistas, mostrando seu potencial.

Esses textos mencionados tratam com simplicidade, com explicações de fácil entendimento, com uma lógica estrutural, linguagem objetiva e distante de burocracia científica.

O artigo QS12 informa que um dos mitos mais difíceis de combater está no seu título, "Tudo não passa de uma conspiração". O argumento principal do texto está pautado na força das organizações institucionalmente respeitadas, como "IPCC, a NASA, a NOAA, e as Academias Nacionais de Ciências de mais de 80 países". Vale destacar que em um trecho o texto afirma que a investigação (referindo-se à pesquisa científica) enfrenta resistência por parte do mundo. Essa afirmativa pode contribuir para uma visão deformada sobre a ciência, como se ela estivesse "fora do mundo", como se ela não fosse influenciada pelos diversos contextos (político, social, cultural, econômico, entre outros) no qual é construída (GIL PEREZ, et al., 2001; FERNÁNDEZ et al., 2005; MOURA, 2014).

Essa afirmativa transmite uma visão descontextualizada que ignora (ou relativiza) as relações ciência, tecnologia e sociedade (CTS). Segundo López-Cerezo (2009), uma abordagem CTS possui justamente a contextualização da ciência e da tecnologia como um dos principais objetivos, assim como a promoção da participação pública nas questões tecnocientíficas.

No artigo SUP01 é possível observar que o texto traz, como proposta, uma possibilidade de enxergar o futuro global em relação ao ambiente. É uma maneira peculiar de utilizar a temática. Seu título - "O futuro - como ele será: ambiente" - indica que o enfoque a ser dado pelo autor está ligado à questão ambiental como um todo, não apenas a um tema ambiental específico. De fato, o texto inicia apresentando um contexto em que o ano de 1987 torna-se um marco, pois no período anterior a essa data o artigo expõe que as maiores preocupações ambientais eram locais: "Até 1987, ambiente era uma questão local. Era a despoluição do rio Tâmisa. Era a atmosfera de Los Angeles e de São Paulo". A partir dessa colocação, o autor apresenta uma mudança de visão significativa que se perpetuaria. Essa mudança foi proporcionada pela observação do "buraco na camada de ozônio" sobre a Antártida, o que fez reunir as lideranças mundiais em torno de uma questão ambiental. Os momentos de reunião de lideranças mundiais (Montreal, Rio 92, Protocolo de Kioto e Rio+20) são citados pelo autor, e, nesse momento, o artigo coloca em destaque o AG como sendo o problema ambiental já conhecido pela comunidade científica e novo alvo da opinião pública. Ao final do texto o autor apresenta os investimentos em energia limpa e renovável como o futuro cenário mundial.

Pode-se inferir que o tema $A G$ não é o principal enfoque do artigo, mas essencial para que o autor consiga desenvolver sua proposta. O AG não recebe, por exemplo, a mesma importância dada ao "buraco da camada de ozônio", uma vez que este é apre- 
sentado como marco histórico. É importante ressaltar, todavia, que, embora no texto o AG não tenha sido o foco principal, o autor utiliza o tema para apresentar possibilidades futuras: "a temperatura do planeta deve aumentar entre $1,1{ }^{\circ} \mathrm{C}$ e $2,9^{\circ} \mathrm{C}$ se forem tomadas políticas pró-ambiente - ou de $2,4{ }^{\circ} \mathrm{C}$ a $6,4{ }^{\circ} \mathrm{C}$, se nada for feito", e apresentar uma única proposta de discussão.

Não há uma preocupação evidente do autor em esclarecer alguns termos e consequências causados pelos problemas ambientais, o que pressupõe um conhecimento implícito do leitor para correlacionar os argumentos do texto. Pressupor esse conhecimento implícito, ou prévio, pode prejudicar o entendimento do texto por parte do leitor se este não o possuir.

Também de uma maneira particular, o texto QSO3 trata da poluição do ar (sobretudo as implicações na saúde das pessoas), empregando o termo AG uma única vez. Utiliza informações da Organização Mundial da Saúde (OMS) para trazer respaldo às suas ponderações e prioriza discutir os poluentes que afetam a qualidade do ar, relacionando ao comportamento da sociedade. $\mathrm{O}$ artigo faz menção ao AG somente neste trecho: "Os gases que destroem a camada de ozônio estratosférica de forma mais agressiva foram banidos e substituídos por compostos mais seguros; hoje a maior ameaça é a do aquecimento global". Em nenhum outro momento o AG é mencionado direta ou indiretamente. Neste texto, é possível perceber que o tema AG não recebe o enfoque principal e não é usado como forma de contextualizar os fatos, e, ainda, que não existe informações claras que apontem para o tema; |a não ser na frase citada anteriormente que coloca o AG como a maior ameaça da saúde humana.

Embora o AG tenha sido utilizado com bastante timidez por esses dois textos (SUP01 e QSO3) de maneira bem particular em relação aos outros textos analisados, é possível perceber alguma relação do tema com o bem-estar social presente e futuro em âmbito global. Casagrande, Silva Junior e Mendonça (2011) asseveram que os fatores climáticos permanecem ligados, em larga escala, ao bem-estar econômico e social, apesar dos avanços científicos e tecnológicos. Além disso, esses autores ressaltam o desafio complexo de entender o comportamento de pessoas e instituições acerca do tema mediante a divulgação do conhecimento científico. Isso está atrelado ao reconhecimento das mudanças climáticas e AG como fator de risco ante o destino da humanidade. Esses dois textos possuem potencial nesse contexto de reconhecimento de fator de risco e relação com o bem-estar socioambiental.

No contexto de artigos que tratam o AG como coadjuvante na organização e encadeamento dos seus argumentos, há um grupo de artigos (SUPO6, QSO5, QSO7 e QS15) que explora o comportamento do clima marcado por eventos extremos. O artigo QSO5 concentra sua discussão na ocorrência de períodos mais frios, colocando que esse fato não justifica a afirmativa que não existe AG. A maior parte dos argumentos no artigo explica o motivo desses períodos mais frios e menciona o tema em dois momentos: "Perante esse clima ártico, não admira que os céticos não acreditem no aquecimento global", e, ao final do artigo, "Embora as flutuações no movimento do ar estejam a enviar tempo frio para América do Norte, Europa e Ásia, a temperatura média está a aumentar". Esse trecho final conecta as explicações sobre os períodos frios com a temática. 
O texto QSO7 também concentra seus argumentos em fatos que apontam contrariamente a existência do AG no intuito de esclarecer e explicar. $O$ artigo menciona que, pelo fato de o planeta ter chegado a temperaturas acima das registradas atualmente em um período bem distante, "durante o Eoceno Inferior" pode haver confusão quanto às causas das alterações climáticas atuais. Ao final o artigo apresenta seu principal argumento, defendendo sua visão antropocêntrica da causa das mudanças climáticas, baseando-se nos modelos climáticos científicos que, ao "contabilizar os efeitos das ações humanas, porém, subitamente, tudo bate certo". Uma das principais controvérsias em relação ao tema é, justamente, a participação antropogênica no AG. Conforme mencionado anteriormente, existem grupos, que se dedicam ao estudo das mudanças climáticas e AG, que investem no reconhecimento das causas sob perspectivas diferentes. É importante levar em consideração, portanto, as diferentes posições ao abordar a temática com vistas ao pleno entendimento crítico do assunto, o que não significa que a revista não tenha liberdade de posicionamento e veiculação de sua convicção aos seus leitores. $\mathrm{O}$ artigo oferece um infográfico que auxilia na visualização de sua defesa (Figura 1).

Figura 1 - Infográfico do artigo QSO7

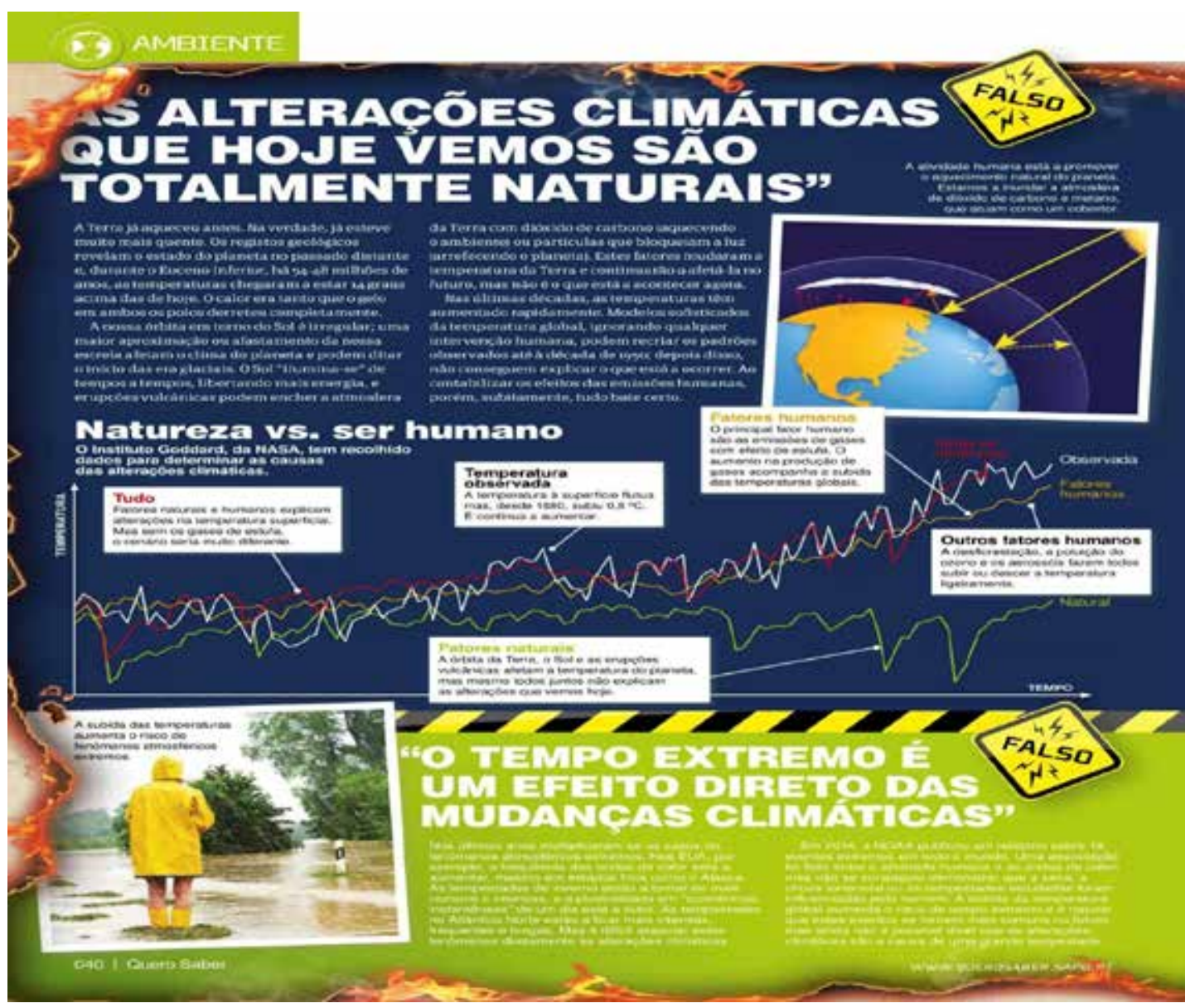

Fonte: Revista Quero Saber.

O artigo QS15 dedica-se a informar o leitor sobre o comportamento da atividade solar, com objetivo que não culpar o Sol pelas alterações climáticas. Assemelha-se ao artigo QSO7 quanto o enfoque dado ao Sol. Menciona que a atividade solar "atravessa 
ciclos de maior atividade a cada 11 anos", e reconhece que esses ciclos de maior atividade culminam em manchas solares intensas, mas afirma que "as tendências de aquecimento nas últimas décadas já não correspondem à atividade solar".

Neste grupo destacamos o texto SUP06. Seu início pontua os episódios de ondas de calor mais frequentes nos últimos anos e relaciona não somente as ondas de calor, mas o aumento da frequência de outros eventos, como alagamentos, número de furacões, secas e invernos rigorosos como principal sintoma das mudanças climáticas. Nesse ponto, o artigo dedica-se a problematizar os eventos que caracterizam as mudanças climáticas, expondo que o comportamento do clima extremo está conectado a outros fatores além do calor. Começa afirmando que "Mudança climática não é sinônimo puro e simples de aumento de temperatura média da Terra" e que outros "processos, que envolvem a possível savanização da Amazônia, o aumento dos desertos e o deslocamento das regiões mais propícias para a agricultura, também estão inclusos no pacote". Nessa problematização, os diversos exemplos e fatos colocados pelo artigo marcam a imprevisibilidade e a aleatoriedade dos fenômenos naturais. Nesse contexto, há mais importância nos eventos extremos citados no artigo do que na relação desses com o AG.

Este artigo, portanto, não possui como foco principal o tema AG mesmo que apresentando fenômenos climáticos que possuem potencial para discutir o tema. Ainda assim, as questões são bem colocadas e os argumentos cumprem o papel de apresentar incertezas e problematizar o comportamento do clima extremo. Dessa forma, o artigo mostrou-se coerente e ponderado, posto que existe uma incapacidade dos modelos climáticos convencionais de reconstruir a variabilidade natural do clima de modo adequado (SCAFETTA, 2016). Encerrar a questão não retrataria a realidade.

Tanto SUP06 quanto QS05, QSO7 e QS15 possuem boa organização das informações e uma abordagem simples, sem necessidade de conhecimento implícito do leitor para a compreensão do texto.

Colocando o AG como coadjuvante, mas em um sentido contrário dos artigos anteriores citados, o artigo QSO8, que tem por título " $O$ tempo extremo é um efeito direto das mudanças climáticas", busca desmistificar a afirmativa expressa em seu título. Apresenta alguns eventos extremos e assume que "é difícil associar esses fenômenos diretamente às alterações climáticas", prendendo-se à fala dos especialistas (um relatório), que conseguiram associar atividade humana às ondas de calor, mas não conseguiram o mesmo com a "seca", "chuva torrencial" e "tempestade".

De fato, não é simples estabelecer relações entre os fenômenos e as causas das mudanças climáticas. Em Oliveira et al. (2017) vemos que existem causas naturais que atuam em três grandes fatores: emissão da radiação (fator primário determinado por variações solares); recepção da radiação (fator secundário determinado por variações da posição terrestre em relação ao Sol); e reflexão, absorção, distribuição do calor e reemissão da radiação (fator terciário determinado por alterações da composição atmosférica, oceanos, etc.). As causas antrópicas, segundo os autores, atuam somente no fator terciário. $\mathrm{O}$ artigo, portanto, foi prudente e cumpriu o papel de problematizar a discussão. 


\section{Enfoque principal}

Em dois artigos o AG recebe enfoque principal: QSO4 e QS13. Em outras palavras, o tema está presente em todo o artigo, participando do encadeamento das informações e argumentos. É possível destacar trechos e perceber que se trata da temática sem que seja necessário ler todo o texto. O artigo QSO4 argumenta sobre o aumento de temperatura em um passado recente e apresenta uma consequência disso; mais adiante menciona novamente sobre o aumento de temperatura, "Nos últimos cem anos, a taxa de aumento de temperatura quase duplicou", e apresenta uma implicação futura mostrando a necessidade de mudança de hábito na humanidade. Essa mudança de hábito é fortemente influenciada pela mídia de massa. Gadea et al. (2017) reconhecem os meios de comunicação como importante recurso para potencializar o desenvolvimento de atitudes e habilidades críticas por meio da veiculação de uma ciência socialmente contextualizada.

O artigo prossegue apresentando algumas consequências ambientais oriundas do aumento de temperatura e a preocupação de governantes e especialistas de buscarem meios de mitigar os efeitos das alterações climáticas. Por fim, encerra argumentando que se "esperarmos para ver como se desenrolam os efeitos dessas alterações, pode ser tarde demais". O tema é essencial na construção dos argumentos pelo texto.

Ao mencionar que existe uma preocupação de governantes, o texto alinha-se com o comportamento recente da sociedade representada em seus diversos atores. O tema tem recebido atenção pública cada vez maior de diversos setores da sociedade que têm aderido às discussões. Oliveira, Carneiro e Vecchia (2017) afirmam que a questão das mudanças climáticas e seus riscos está na agenda da mídia de massa, coincidindo com a crescente atenção política e científica. Além disso, a cobertura dessa mídia pode contribuir na compreensão do público, mesmo moldando e afetando o discurso político.

No artigo QS13 o tema também é essencial para o desenvolvimento do texto. Este artigo tem por título "Alguns graus não farão qualquer diferença", com o objetivo derrubar essa afirmativa expressa no título. Desde o início utiliza da temática para fundamentar vários problemas ambientais em âmbito global. A cada menção ao aumento de temperatura o autor faz uma contextualização com algum problema resultante desse aumento. Também sinaliza a temática diretamente, mencionando os termos: "aquecimento global", "aquecimento", "aumento de temperatura" e "subida de temperatura".

Os artigos possuem boa concatenação de ideias; ambos utilizam uma linguagem de fácil entendimento, objetiva, do cotidiano do leitor, sem a necessidade de conhecimento implícito por este. Não se observou erros conceituais; aliás, em nenhum texto analisado da Revista Quero Saber houve imprecisões científicas. O artigo QS13 ainda conta com um infográfico que ilustra e complementa as colocações feitas no texto.

\section{Causador de desequilíbrios ambientais}

Ao analisar todas as reportagens foi possível perceber, somente em alguns textos da Superinteressante, uma maneira de abordar o tema como causador de desequilíbrio ambiental. A temática é colocada como responsável de causar outros tipos de problemas ambientais, como se a temática causasse "efeitos colaterais" no ambiente. 
O texto SUPO4 trata de uma enorme bolha de gás metano identificada sob o gelo da Sibéria, que pode vir a ser liberada por consequência do AG. $O$ autor desenvolve 0 texto a partir do posicionamento dos pesquisadores que identificaram a bolha de metano, contextualizando as consequências ambientais possíveis caso a bolha seja liberada, e mostrando que existe posicionamento contrário por parte de outros pesquisadores. O AG está presente no contexto deste artigo, mas não recebe o enfoque principal do texto. Quando aparece de forma explícita, é utilizado para justificar os argumentos do autor, proporcionando-Ihe um contexto de relevância. Percebemos isso no seguinte momento:

"O problema é que, com o aquecimento global, o gelo da Sibéria está derretendo - e pode deixar o metano escapar para a atmosfera, onde ele provocaria um desastre ambiental", e, "(...) o metano retém muito calor: 23 vezes mais do que o CO2, atual vilão do aquecimento global".

Os argumentos são bem trabalhados, não se encontram fragmentados e existe uma construção clara dos argumentos. Sobre os termos "metano", "materiais orgânicos", "Sibéria", dedicou a explicar ou contextualizá-los; mas sobre os termos "aquecimento global" e " $\mathrm{CO}_{2}$ " não teve a mesma dedicação. Isso permite-nos afirmar que o texto pressupõe que o leitor tenha conhecimentos prévios sobre o tema.

No artigo SUP05 o AG está bem mais presente. O termo aparece mais vezes, desde o início até o final, e, mesmo quando o termo não aparece, expressões usadas pela autora apontam para o tema AG, por exemplo: "aumento de temperatura" e "dias mais quentes". O artigo tem como temática principal os tornados, a expectativa do aumento desse evento e a causa disso. Inicia apresentando alguns dados sobre a passagem de tornados nos Estados Unidos (EUA) e, já de imediato, sinaliza o AG como determinante nessa expectativa: "A cada ano, mais de mil tornados atingem o país (...). E a expectativa é de que esses números aumentem. Pode pôr na conta do aquecimento global".

Os argumentos da autora possuem uma sequência de construção: são desenvolvidos a partir de informações científicas de um grupo de pesquisadores, traz explicações envolvendo o fenômeno (tornado) e, ao final, dedica mais atenção ao tema AG, traçando uma relação entre o fenômeno e o AG (Figura 2). Essa atenção tem o propósito de contextualização, dar maior relevância ao texto e retomar seu argumento de culpar o AG pelo quadro apresentado no artigo. Faz parte da argumentação da autora a explicação do motivo pelo qual os tornados devem aumentar pelo mundo. Ela busca fazer isso por meio de uma linguagem simples e utilizando figuras de linguagem.

O artigo SUP08 também coloca o AG como responsável por causar problemas, mas o problema apresentado no texto não é ambiental, e sim econômico. Este artigo apresenta dados de uma pesquisa que relacionou a produtividade dos países e o AG. Segundo o artigo, este estudo concluiu que "a produtividade de um país diminui enquanto a sua temperatura aumenta", baseado em dados econômicos de 166 países no período de 1960 até 2010. Além da conclusão, há uma projeção de futuro que o artigo destaca: "Até 2100, 77\% dos países vão sofrer as consequências econômicas da queda de produtividade". Nessa projeção, a autora do texto salienta que o clima é capaz de remodelar o mundo e que os países nas regiões mais quentes sofrerão ainda mais. 0 texto não é extenso, traz como informações dados de um estudo e consegue estabele- 
cer a relação de causa entre o AG e a atividade econômica de um país. Por utilizar uma linguagem simples, objetiva e comum do cotidiano, não requer do leitor algum tipo de conhecimento implícito. Abordar o tema em um contexto que ultrapassa o científico e o ambiental mostra o potencial de transversalidade do tema. A análise das possibilidades de contextos será feita na categoria Abordagens e contextos mais adiante.

Figura 2 - Trecho final do artigo SUP05

\begin{abstract}
Eis a importância da pesquisa: ela demonstrou que, ao contrário do que se pensava, o aquecimento global não diminui o cisalhamento, mas favorece o seu aumento em dias de alto CAPE. Nesses dias mais quentes, a umidade e o vento, as duas crias do aquecimento global, se juntam e causam as grandes tempestades - que costumam anteceder a chegada de grandes tornados. Em marcha lenta ou prestes a acelerar, o aquecimento global prossegue. Resta torcer para que os tornados errem $\mathrm{o}$ alvo.
\end{abstract}

Fonte: Revista Superinteressante.

Como pode ser observado, o AG recebeu diversos enfoques nos artigos analisados. Em sua grande maioria, o tema não ocupou a centralidade na construção da argumentação, isto é, os argumentos e informações colocadas nos artigos nem sempre apontam para o tema, mas o utiliza sobre diversos propósitos. Existe um aspecto positivo nesse ponto. Essa diversidade de enfoque mostra a capacidade de amplitude temática, que se traduz em alcançar o maior número de indivíduos em um maior número de situações possíveis (NEIVA, 2016). Em outras palavras, nas Revistas Superinteressante e Quero Saber o tema AG consegue atender a leitores e interesses diversos.

\title{
ABORDAGENS E CONTEXTOS
}

Foi possível perceber, em alguns artigos, possibilidades de estabelecer relação dos argumentos do texto com um contexto diferente do contexto científico. Em outras palavras, existem informações que oferecem a possibilidade de discussão - e, a partir disso, estabelecer relação - que ultrapassa o âmbito científico.

Observamos que os artigos SUP01, SUP05, SUP06, SUPO9, QSO2, QSO3, QSO7, $Q S 12, Q S 13$ e $Q S 15$ possuem potencial para estabelecer relações com os contextos de saúde, político, cotidiano social, histórico e socioeconômico.

O contexto político pode ser explorado nos textos SUP01 e QS12. O texto SUP01 abre a possibilidade de discussão no contexto político ao mencionar que o enorme buraco sobre a superfície terrestre causou tanto medo que, "pela primeira vez, líderes de países do mundo inteiro se reuniram em torno de uma questão ambiental". Os principais argumentos no artigo apontam para possível futuro do ambiente, e o contexto político não é argumento principal nesse artigo, e sim, o científico. O artigo QS12 afirma que "Muitas pessoas são automaticamente céticas perante qualquer evidência apresentada por especialistas em clima", apontando diretamente para o público geral. O contexto que este artigo consegue (ou pretende) estabelecer conexão está (bem mais explícito que no SUP01) na seguinte colocação: "Esta não é só uma questão científica, mas também política". Essa argumentação axial no âmbito científico, com abertura para discus- 
são no âmbito político, corrobora a afirmativa feita por Loose, Lima e Carvalho (2014), de que os macroenquadramentos das notícias são predominantemente científicos e políticos. Talvez porque a menção ao contexto político, geralmente, é mais direta: "líderes de países", e "mas também político".

Conseguir relacionar o tema ao cotidiano promove uma aproximação do leitor, quando ele percebe que os argumentos e informações colocadas não são distantes do seu dia a dia. Essa aproximação é de extrema importância, pois, conforme Calero, Vilches e Gil Perez (2013), incorporar os sujeitos, que habitualmente estão fora da comunidade científica, na participação em pesquisas e tomadas de decisão, é essencial para definir e viabilizar práticas viáveis de uma "ciência sustentável". A aproximação é o primeiro passo para essa participação.

Nesse sentido de relacionar as informações ao cotidiano do seu leitor, os artigos SUP05 e SUPO6 oferecem possibilidade de trabalhar no âmbito do cotidiano social. 0 texto SUP06, que trata de apresentar eventos extremos para caracterizar o clima extremo vivido no período atual, em determinado momento apresenta uma informação com potencial para discutir o tema além do contexto científico: "as chuvas e deslizamentos de terra no verão de 2011, na região serrana do Rio de Janeiro, que mataram cerca de mil pessoas - a maior tragédia natural da história do Brasil". Essa informação traz o tema para o cotidiano das pessoas, pois consegue colocar os argumentos científicos do texto influenciando (ou refletindo) no dia a dia dos indivíduos. De igual modo, o texto SUP05 consegue estabelecer essa relação direta entre o conhecimento e o cotidiano social: "o tornado varreu a cidade de Moore e matou 50 pessoas. A cada ano, mais de mil tornados atingem o país, principalmente na primavera".

O artigo SUPO9, que aponta a dificuldade econômica em combater o gás carbônico mediante duas formas - queimando menos combustíveis fósseis e aumentando a área coberta por florestas -, também abre a possibilidade de interação do tema com o contexto socioeconômico quando coloca: "talvez seja possível se livrar do $\mathrm{CO}_{2}$ ganhando dinheiro". Também de maneira simples e direta, o contexto socioeconômico pode ser relacionado à informação colocada pelo artigo QS13. Sem aprofundar no argumento, este artigo traz que o aumento da temperatura "acarreta um risco aumentado de fenômenos extremos, como secas, inundações e tempestades que podem ter efeitos devastadores sobre populações, economia e, é claro, o ambiente". Mesmo sendo sucintas, essas mensagens pertencem ao conjunto de informações apresentadas nos textos com o intuito de problematizar o aumento da temperatura. Essa postura problematizadora, que contribui na discussão, mas não a encerra, está de acordo com a afirmação feita por Lima e Giordan (2017) quando mencionam, no âmbito do ensino, que a DC contribui para a contextualização, para a produção de sentidos e para a problematização.

Dois artigos abrem possiblidade para a discussão no contexto histórico: QSO7 e QS15. No texto QSO7, a perspectiva histórica é timidamente presente, mas se manifesta em duas colocações: "A Terra já aqueceu antes. Na verdade esteve muito mais quente", e também em: "Nas últimas décadas, as temperaturas têm aumentado rapidamente". Essa perspectiva histórica faz parte dos argumentos que constroem a ideia central do artigo. Da mesma forma, no artigo QS15 as seguintes colocações conseguem possibilitar relações com o contexto histórico: "... ciclos de maior atividade a cada 11 anos"; "No 
passado, estes ciclos e mudanças estavam associados a flutuações da temperatura"; e, por fim, “... houve um mínimo solar entre 2007 e 2009 mas as temperaturas na Terra continuaram a subir". As colocações, nos dois artigos, contribuem na construção dos argumentos, mesmo não sendo peça central nessa construção. Vale ressaltar que o artigo QS07 possui claramente uma visão antropocêntrica do tema, uma vez que argumenta em favor do modelo sofisticado de temperatura global que contabiliza a intervenção humana no clima.

Essa possibilidade de dialogar as questões científicas com o contexto histórico é relevante para responder às questões do nosso cotidiano, pois estão inseridas em uma rede dinâmica da qual o aspecto histórico faz parte (MOURA; GUERRA, 2016).

Em QSO3, em meio aos argumentos disponibilizados pelo texto, uma colocação possibilita estabelecer o tema ao contexto de saúde pública em âmbito mundial: "De acordo com a Organização Mundial de Saúde, a inalação de ar poluído causa anualmente sete milhões de mortes prematuras". Ao fazer um aponte entre o problema de poluição atmosférica e o problema de saúde pública, o artigo mostra o potencial em aproximar o leitor (público não especializado) instigando seu interesse pela temática mesmo que indiretamente. Talvez apresentar os diversos poluentes atmosféricos, muitas vezes que nem são produzidos pela ação individual do cidadão, não consiga prender ou mostrar a relevância do tema ao leitor. Relacionando ao contexto de saúde, no entanto, o interesse dos cidadãos pode ser despertado.

O artigo QSO2 consegue relacionar a poluição do ar à possibilidade de controle, apresentando um fato ocorrido em Londres no ano de 1952, quando medidas foram tomadas a partir de problemas de saúde com origem na poluição do ar: "O Grande Nevoeiro/Smog de 1952 em Londres terá morto 12.000 pessoas em quatro dias; quatro anos depois, o Clean Air Act foi aprovado e a qualidade do ar melhorou". Aqui possibilita-se a discussão do tema nos contextos de saúde, político e histórico.

Fraga e Rosa (2015) inferem que existe uma dimensão social singular na DC, posto que a ciência está consolidada na organização da sociedade e no cotidiano social, mas nem sempre é fácil estabelecer a relação entre o conhecimento produzido nas pesquisas científicas e nossas atitudes diárias. Nesse sentido, a DC tem potencial de aproximar os envolvidos, pois utiliza da contextualização justamente para estabelecer essa relação. É o que acontece nos artigos citados quando permitem a correlação nos mais diversos contextos aqui observados.

\section{CONSIDERAÇÕES FINAIS}

Uma DC crítica, contextualizada, comprometida com a veiculação da informação na linguagem apropriada e relacionada ao cotidiano social, insere-se nesse contexto de formação da cidadania muito além do simples compartilhar conhecimento. Embora exista diversidade de perspectivas, pluralidade de definições na literatura, percepções, metodologias variadas, ações, intenções, entre outros aspectos, a DC move-se na direção de aproximar dois públicos: o especializado e não especializado (público geral). 
É possível observar alguns pontos de aproximação entre a Superinteressante e a Quero Saber. Tratando-se de organização e apresentação das informações, ressaltamos o encadeamento dos argumentos, que facilita a leitura e a assimilação das informações colocadas nos artigos das duas revistas. Elas possuem uma fluidez que pode estar relacionada à figura do jornalista (alguém próprio da área de comunicação), que é o responsável por elaborar os textos nas duas revistas, embora a presença do especialista (pesquisador, instituição de pesquisa, organização, grupos de pesquisa, etc.) seja marcada por falas, dados científicos e estudos. Alguém da área da comunicação na elaboração dos artigos possui esse ponto positivo: fluidez, concatenamento de ideias e linguagem próxima do público não especialista. Em contrapartida, a falta de conhecimento técnico mais apurado desses profissionais da comunicação pode favorecer a recorrência de imprecisões científicas, o que exige atenção ao uso do material.

As revistas assemelham-se também na atenção dada ao tema AG. Em seus artigos, verificou-se uma diversidade de enfoque. A temática recebeu centralidade somente em QSO4 e QS13, indicando que o AG pode ser utilizado como protagonista na mídia impressa e tem potencial para isso. Essa diversidade de enfoque demonstra que o tema possui uma amplitude temática e um caráter interdisciplinar e transversal. Isso é corroborado pelo fato de a temática ser discutida em diversos setores da sociedade, sendo pauta de eventos políticos globais, servindo como conhecimento base para medidas gerenciais nos países, etc.

Conseguir relacionar os conhecimentos científicos ao cotidiano do público não especialista também faz parte do papel social da DC. Assim, a contextualização, que proporciona o sentimento de proximidade no público, é aquela que o leva ao ambiente de construção do saber científico por meio da veiculação das informações que são naturais da comunidade científica, isto é, o público é levado a ter contato com esse ambiente, e traz ao seu convívio as informações divulgadas, conseguindo estabelecer relações com os diversos contextos no cotidiano. Os textos analisados demonstram que a temática oferece possibilidades de estabelecer relações com diversos contextos, sobretudo de saúde, político, cotidiano, social, histórico e socioeconômico. Essa capacidade de contextualização dos textos demonstra um esforço em buscar veicular uma informação aberta para a discussão, uma informação que é dinâmica, que não se encerra no âmbito científico. A DC, nesse sentido, oferece oportunidade de aproximação entre os públicos (especialista e não especialista), e, além disso, ela contribui para o desenvolvimento de uma concepção mais próxima da realidade científica.

O que sugerimos, a partir de nossos resultados, é que o tema ganhe maior protagonismo, que não sirva apenas para contextualizar, respaldar ou trazer relevância a outros temas, e que a discussão venha a estar mais próxima da realidade que cerca a temática, longe de consensos absolutos, com grande caráter de urgência, distante da simplificação exagerada. O AG detém o potencial de nos fazer olhar para o futuro, avaliando o passado e requerendo tomadas de decisão no presente.

Novas pesquisas são necessárias para que o tema AG continue sendo analisado, explorando todo seu potencial interdisciplinar, transversal, de contextualização e de amplitude temática. 


\section{REFERÊNCIAS}

BARDIN, L. Análise de conteúdo. Lisboa: Edições, 2002.

CALERO, M.; VILCHES, A.; GIL PEREZ, D. Necesidad de la Transición a la Sostenibilidad: papel de los medios de comunicación en la formación ciudadana. Didáctica de las Ciencias Experimentales y Sociales, n. 27, p. 235-254, 2013.

CASAGRANDE, A.; SILVA JUNIOR, P.; MENDONÇA, F. Mudanças climáticas e aquecimento global: controvérsias, incertezas e a divulgação científica. Revista Brasileira de Climatologia, v. 7, p. 30-44, 2011.

COOK, J. et al. Quantifying the consensus on anthropogenic global warming in the scientific literature. Environmental Research Letters, v. 8, n. 2, p. 1-7, 2013.

FERNÁNDEZ, l. et al. ¿Qué visiones de la ciencia y la actividad científica tenemos y transmitimos? In: GIL PÉREZ, D. et al. (ed.). ¿Cómo promover el interés por la cultura científica? Una propuesta didáctica fundamentada para la educación científica de jóvenes de 15 a 18 años. Santiago de Chile: Orealc; Unesco, 2005. FERREIRA, P. S. et al. As perspectivas e divergências acerca do aquecimento global antropogênico. Caderno de Geografia, v. 27, n. 51, 2017.

FRAGA, F. B. F. F.; ROSA, R. T. D. Microbiologia na revista Ciência Hoje das Crianças: análise de textos de divulgação científica. Ciênc. Educ., Bauru, v. 21, n. 1, p. 199-218, 2015.

GADEA, l. et al. Contribución de la prensa a la educación científica y tecnológica. Enseñanza de las ciencias: revista de investigación y experiencias didácticas, n. Extra, p. 1.567-1.572, 2017.

GIL PÉREZ, D. et al. Para uma imagem não deformada do trabalho científico. Ciência \& Educação, v. 7, n. 2, p. 125-153, 2001.

GODOY, A. S. Pesquisa qualitativa: tipos fundamentais. Revista de Administração de empresas, v. 35, n. 3, p. 20-29, 1995.

GOMES, I. A. A divulgação científica em Ciência Hoje: características discursivo-textuais. 2000. Tese (Doutorado em Linguística) - Universidade Federal de Pernambuco, Recife, 2000.

LIMA, G. S.; GIORDAN, M. Propósitos da divulgação científica no planejamento de ensino. Revista Ensaio, Belo Horizonte, n. 19, p. 1-23, 2017.

LOOSE, E. B.; CARVALHO, A. O que pensam os jornalistas sobre seu papel no enfrentamento das mudanças climáticas: as percepções dos profissionais da Gazeta do Povo no Paraná, Brasil. Razón y Palabra, v. 19, n. 91, 2015.

LOOSE, E. B.; LIMA, M.; CARVALHO, A. Estudo dos enquadramentos sobre mudanças climáticas no jornal brasileiro Gazeta do Povo. In: PINTO-COELHO, Z.; ZAGALO, N. Comunicação e Cultura, III Jornadas Doutorais, Ciências da Comunicação e Estudos Culturais. Braga: Centro de Estudos de Comunicação e Sociedade; Universidade do Minho, 2014. p. 139-156. ISBN 978-989-8600-26-4.

LÓPEZ-CEREZO, J. A. Ciencia, Tecnología y Sociedad: el estado de la cuestión en la Europa y Estados Unidos. In: Educación, Ciencia, Tecnología y Sociedad, Documentos de trabajo, Centro de Altos Estudios Universitarios de la OEI, n. 3, p. 23-36, 2009.

LÜDKE, M.; ANDRÉ, M. E. D. A. Pesquisa em educação: abordagens qualitativas. São Paulo: EPU, 1986.

MOURA, B. A. O que é natureza da ciência e qual sua relação com a história e filosofia da ciência? Revista Brasileira de História da Ciência, Rio de Janeiro, v. 7, n. 1, p. 32-46, 2014.

MOURA, C. B.; GUERRA, A. História cultural da ciência: um caminho possível para a discussão sobre as práticas científicas no ensino de ciências? Revista Brasileira de Pesquisa em Educação em Ciências, v. 16, n. 3, p. 725-748, 2016.

NEIVA, R. A. Mudanças climáticas na mídia: jornalismo e agricultura no contexto do aquecimento global. 2016. Dissertação (Mestrado) - Universidade Estadual de Campinas, Instituto de Estudos da Linguagem, São Paulo, 2016.

OLIVEIRA, L. T.; CARVALHO, A. Public Engagement with Science and Technology: contributos para a definição do conceito e a análise da sua aplicação no contexto português. Observatorio (OBS*) Journal, v. 9, n. 3, p. 155-178, 2015.

OLIVEIRA, M. J.; CARNEIRO, C. D. R.; VECCHIA, F. A. da S. Evolução (2004-2017) do interesse mundial pelas mudanças climáticas e aquecimento global: influência da ciência, mídia, política, economia e controvérsias. Revista Científica Anap Brasil, v. 10, n. 20, 2017.

OLIVEIRA, M. J. et al. Ciclos climáticos e causas naturais das mudanças do clima. Terræ Didatica, v. 13, n. 3, p. 149-184, 2017.

ROCHA, M. B. Contribuições da divulgação científica na formação ambiental de estudantes da educação básica. Trilhas Pedagógicas, v. 7, n. 7, p. 172-184, ago. 2017. 


\section{\& Contexto}

Igor Leandro Alves de Carvalho - Marcelo Borges Rocha

SABBATINI, M. Novos modelos da percepção pública da ciência e da tecnologia: do modelo contextual de comunicação científica aos processos de participação social. ENCONTRO DOS NÚCLEOS DE PESQUISA DA INTERCOM, 4., 2004. Trabalho apresentado ao NP 9 - Comunicação Científica e Ambiental. Salamanca: Intercom, 2004.

SANTOS, A. M.; GALVÍNCIO, J. D.; MOURA, M. S. B. Os recursos hídricos e as mudanças climáticas: discursos, impactos e conflitos. Revista Geográfica Venezolana, v. 51, n. 1, p. 59-68, 2010.

SCAFETTA, N. Problems in Modeling and Forecasting Climate Change: CMIP5 General Circulation Models versus a Semi-Empirical Model Based on Natural Oscillations. International Journal of Heat and Technology, v. 34, p. 435-442, 2016.

SCHMIDT, A.; IVANOVA, A.; SCHÄFER, M. S. Media attention for climate change around the world: A comparative analysis of newspaper coverage in 27 countries. Global Environmental Change, v. 23, n. 5, p. 1.233-1.248, 2013.

SILVA, H. C. O que é divulgação científica? Ciência \& Ensino, v. 1, n. 1, p. 53-59, dez. 2006.

WOITOWICZ, K. J. Contribuições da folkcomunicação para o jornalismo cultural: Conteúdos jornalísticos sobre patrimônio no site Cultura Plural. In: CONFERÊNCIA BRASILEIRA DE FOLKCOMUNICAÇÃO. 2017. Recife-PE. Anais [...]. Recife, PE, 2 a 5 de maio, 2017. 